\title{
Nonlinear Model Predictive Control for Hydrogen Production in an Ethanol Steam Reformer with Membrane Separation
}

\author{
Eloi Pérez Contreras* ${ }^{1}$, Maria Serra Prat ${ }^{1}$, Carlos Ocampo-Martinez, Senior Member, IEEE, ${ }^{1}$ and Jordi Llorca ${ }^{2}$ \\ ${ }^{1}$ Institut de Robòtica i Informàtica Industrial (CSIC - UPC), Universitat Politècnica de Catalunya, Llorens i Artigas 4-6, 08028 Barcelona, Spain \\ ${ }^{2}$ Institut de Tècniques Energètiques, Universitat Politècnica de Catalunya, Diagonal 647, Ed. ETSEIB, 08028 Barcelona, Spain
}

\begin{abstract}
This paper presents a new Nonlinear Model Predictive Control (NMPC) design for an Ethanol Steam Reformer with Pd-Ag membrane separation stage. The reformer is used to produce pure hydrogen able to feed a Proton Exchange Membrane Fuel Cell. Mass and energy balances are used to obtain the nonlinear dynamic model of both the reforming and the separation stages. Constraints, system nonlinearities and flexible cost function are the main reasons to select an NMPC controller, which is tested against the ordinary differential equations as simulation model, and has an internal model based on the sample data technique.
\end{abstract}

\section{INTRODUCTION}

Hydrogen is a promising energy vector that presents many advantages in stationary and mobile applications. For example, hydrogen powered fuel cells have more than two times efficiency over traditional combustion engines. However, to transport and store hydrogen has some technical difficulties, and this makes in situ hydrogen production interesting for many applications. Hydrogen can be obtained in different ways, having the reformation of Natural Gas the highest production nowadays [1]. This work is focused on the production of pure hydrogen from ethanol, which is a renewable, biodegradable, low toxicity and easy to transport energy source. Specifically, this work studies hydrogen production through an Ethanol Steam Reforming process [2]. Cobaltbased catalyst is considered because of its lower operating temperature and the highest $\mathrm{H}_{2} / \mathrm{CO}$ ratio in comparison with other catalysts. A Pd-Ag membrane separation stage is set in series with the reformation stage to purify the hydrogen of other chemical components, specially $\mathrm{CO}$, which can poison the Proton Exchange Membrane Fuel Cells [3].

In spite of the literature addressed to catalytic steam reforming of ethanol from a chemical point of view, few works in the literature describe the physical design and the dynamics of Ethanol Steam Reformers. This work is based on a nonlinear one-dimensional dynamic model that corresponds to a real system which integrates the reforming stage and the separation stage into a single shell [4], [5].

\footnotetext{
${ }^{*}$ Corresponding author.

Email addresses:

eloi.perez.contreras @gmail.com (E. Pérez)

maserradiri.upc.edu (M. Serra)

cocampo@iri.upc. edu (C. Ocampo-Martinez)

jordi.llorca@upc.edu (J. Llorca)
}

The multivariable control objective set in this work is to satisfy the desired amount of hydrogen production with minimal ethanol consumption. At the same time, the proposed multivariable control configuration must respect some constraints and handle the high nonlinearities present in the reforming system. Only a few preliminary works are focused on the design of controllers for Ethanol Steam Reformers [3], [4]. In this work, a Nonlinear Model Predictive Control (NMPC) strategy is designed, as main contribution, and results show an appropriate tracking of hydrogen production provided that, in the cost function, enough priority is given to the tracking of hydrogen production with respect to the ethanol consumption minimization.

The remainder of the paper is organized as follows. Section II briefly describes both the physical and chemical system properties. Section III develops mass and energy balances to obtain the system mathematical model and analyzes it. Section IV presents the NMPC for the considered system. Section $\mathrm{V}$ presents and discusses the NMPC simulation results. Finally, conclusions are drawn in Section VI.

\section{SYSTEM DESCRIPTION}

\section{A. Physical Description}

The Ethanol Steam Reformer with membrane separation stage modeled in this work corresponds to a laboratory real system like the one showed in Figure 1 [5]. The upper part corresponds to the reforming stage and the lower part corresponds to the separation stage. The whole reaction and separation chamber measures $230 \mathrm{~mm}$ tall and $22 \mathrm{~mm}$ outside diameter and has a lower head to allow the exit of the hydrogen stream permeated through the membrane. A serpentine conduct around the reactor is used to evaporate the ethanol and water before entering the reforming stage. Five catalytic honeycomb pieces of $2 \mathrm{~cm}$ length each one, loaded with a total of $1.32 \mathrm{~g}$ of cobalt-based catalyst are disposed in series into the reforming (upper) part. In the separation part, a $\mathrm{Pd}-\mathrm{Ag}$ membrane tube is centrally positioned. The pine hole free and dead-end membrane tube measures $76 \mathrm{~mm}$ tall, $1 / 8$ inch diameter and has a total area of $7.1 \mathrm{~cm}^{2}$. The Pd$\mathrm{Ag}$ active layer is $30 \mu \mathrm{m}$ thick over a porous stainless steel support. 


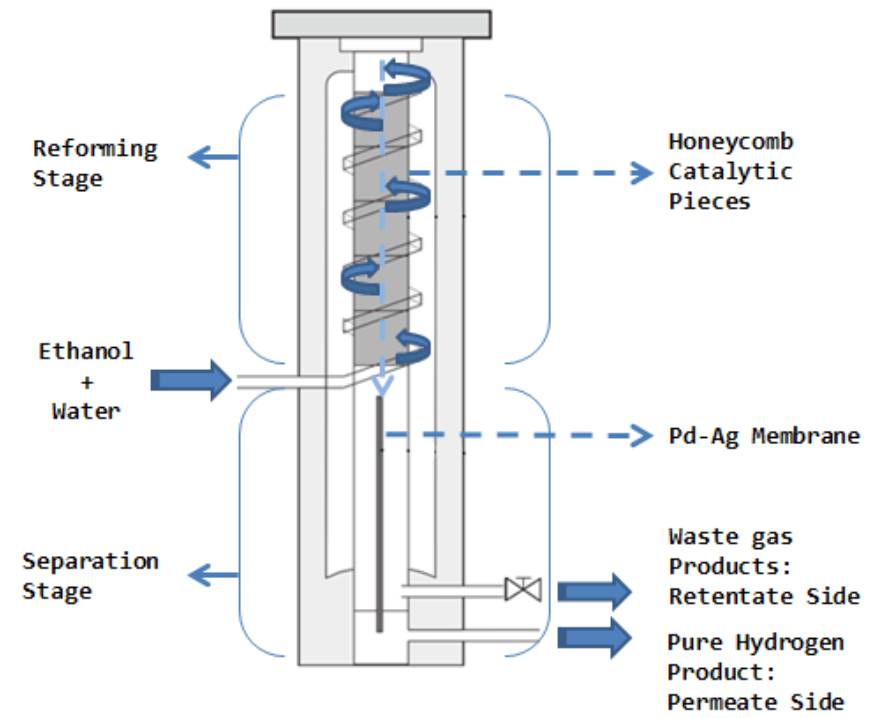

Fig. 1. Staged membrane reactor scheme

\section{B. Chemical Description}

The overall ethanol reforming reaction is based on the production of hydrogen and carbon dioxide from water and ethanol in a molar ratio of 3:1, i.e.,

$$
\mathrm{C}_{2} \mathrm{H}_{5} \mathrm{OH}+3 \mathrm{H}_{2} \mathrm{O} \longrightarrow 6 \mathrm{H}_{2}+2 \mathrm{CO}_{2} \text {. }
$$

However, in the Ethanol Steam Reformer loaded with cobaltbased catalysts, the overall reaction is split into different reactions that take place simultaneously in the same space and conditions [6]. Therefore, this Ethanol Steam Reformer must be modeled as a complex chemical reactor, without using the conversion rate $X[\%]$. The main reactions are the following:

$$
\begin{aligned}
\mathrm{C}_{2} \mathrm{H}_{5} \mathrm{OH} & \longrightarrow \mathrm{CH}_{3} \mathrm{CHO}+\mathrm{H}_{2}, \\
\mathrm{C}_{2} \mathrm{H}_{5} \mathrm{OH} & \longrightarrow \mathrm{CO}+\mathrm{CH}_{4}+\mathrm{H}_{2}, \\
\mathrm{CO}+\mathrm{H}_{2} \mathrm{O} & \rightleftarrows \mathrm{CO}_{2}+\mathrm{H}_{2}, \\
\mathrm{CH}_{3} \mathrm{CHO}+3 \mathrm{H}_{2} \mathrm{O} & \longrightarrow \mathrm{CO}_{2}+5 \mathrm{H}_{2} .
\end{aligned}
$$

Firstly, ethanol dehydrogenates into hydrogen and acetaldehyde (2a), which is further reformed with water to carbon dioxide and hydrogen (2d). In addition, ethanol is also decomposed into carbon monoxide and methane according to the undesired reaction (2b). Also, cobalt catalysts are active for the water gas shift reaction (2c) under typical operating conditions. In the separation stage, the $\mathrm{Pd}-\mathrm{Ag}$ membrane permeates only the hydrogen and leaves the waste gases in the retentate side.

\section{Mathematical Modeling}

In this section, a mathematical model of the Ethanol Steam Reformer described in Section II is presented. It is based on mass and energy balances of a Plug Flow Reactor [15]. Due to the dimensions of the system, the concentration and speed radial profiles are developed in a small distance and thus, only the axial direction variations are considered in the model [7], [8]. Moreover, all the honeycomb subchannels operate in the same way [9], [10], [11], and therefore, the reactor will be treated as a single channel. It is also assumed that pressure remains constant throughout the reactor [12], [13]. With respect to the thermal model, the next assumptions are considered: the temperature of the solid phase is equal to the gas phase [14], and only axial heat convection is modeled as heat transfer mechanism.

\section{A. Mass Balance}

The mass balance of a chemical component in a PlugFlow Reactor, which describes its dynamics, is shown in the following set of mathematical expressions [16]:

$$
\begin{aligned}
\frac{\partial C_{i}}{\partial t}+\frac{\partial\left(v C_{i}\right)}{\partial z} & =r_{i}, \quad i=1,2, \ldots, 7, \\
C_{i}(0, z) & =C_{i, 0}(z) \quad z \in[0, L], \\
C_{i}(t, 0) & =C_{i, i n}(t) \quad \forall t>0,
\end{aligned}
$$

being (3b) and (3c) the boundary and initial conditions, where $i$ is the reaction component (ethanol, hydrogen, carbon monoxide, methane, acetaldehyde, carbon dioxide and water), $C_{i}\left[\frac{\mathrm{mol}}{\mathrm{m}^{3}}\right]$ is the molar concentration of each component, $v$ $\left[\frac{\mathrm{m}}{\min }\right]$ is the linear velocity of gases, $t[\mathrm{~min}]$ is the time, $z[\mathrm{~m}]$ is the axial coordinate, $L[\mathrm{~m}]$ is the catalytic reactor length and $r_{i}\left[\frac{\mathrm{mol}}{\mathrm{m}^{3} \cdot \mathrm{min}}\right]$ is the reaction velocity of each chemical component defined as

$$
r_{i}=\sum_{j=1}^{N} r_{j} v_{i j}, \quad j=1,2, \ldots, 4
$$

where $v_{i j}$ [adim] is the stochiometric ratio of component $i$ in reaction $j$ and $r_{j}\left[\frac{\mathrm{mol}}{\mathrm{m}^{3} \cdot \mathrm{min}}\right]$ is the velocity of reaction $j$. The reaction velocities related to (2a)-(2d) are the following:

$$
\begin{aligned}
r_{1} & =k_{1} P_{\mathrm{C}_{2} \mathrm{H}_{5} \mathrm{OH}}, \\
r_{2} & =k_{2} P_{\mathrm{C}_{2} \mathrm{H}_{5} \mathrm{OH}}, \\
r_{3} & =k_{3}\left(P_{\mathrm{CO}} P_{\mathrm{H}_{2} \mathrm{O}}-\frac{P_{\mathrm{CO}_{2}} P_{\mathrm{H}_{2}}}{k_{W G S}}\right), \\
r_{4} & =k_{4} P_{\mathrm{CH}_{3} \mathrm{CHO}} P_{\mathrm{H}_{2} \mathrm{O}}^{3}, \\
k_{W G S} & =e^{\left(\frac{4577.8}{T}-4.33\right)}, \\
k_{j} & =k_{\infty j} e^{\left(-E_{a_{j}\left(\frac{1}{R T}-\frac{1}{R T_{r e f}}\right)}\right)},
\end{aligned}
$$

where $k_{\infty j}$ are the pre-exponential factors, $k_{j}$ are the kinetic constants, $k_{W G S}$ is the water gas shift kinetic constant and $E_{a_{j}}$ $\left[\frac{\mathrm{J}}{\mathrm{mol}}\right]$ are the activation energies of each reaction, given in [5]. $T[\mathrm{~K}]$ is the temperature, $T_{r e f}$ is the reference temperature, equal to $773 \mathrm{~K}, P_{\mathrm{C}_{2} \mathrm{H}_{5} \mathrm{OH}}, P_{\mathrm{CO}}, P_{\mathrm{H}_{2} \mathrm{O}}, P_{\mathrm{CO}_{2}}, P_{\mathrm{CH}_{3} \mathrm{CHO}}[\mathrm{bar}]$ correspond to the partial pressure of each component and $\mathrm{R}$ $\left[\frac{\mathrm{J}}{\mathrm{mol} \cdot \mathrm{K}}\right]$ is the ideal gas constant.

Additionally to the reaction velocities, the linear velocity of gases $v$ is needed to solve the partial differential equations in (3a). Thus, $v$ can be determined through the following 
sequence of computations [17]:

$$
\begin{aligned}
F_{i} & =\int r_{i} \partial V, \\
F_{\text {Total }} & =\sum_{i=1}^{N} F i, \quad i=1,2, \ldots, 7 \\
F_{\text {Total }, \text { in }} & =F_{\mathrm{C}_{2} \mathrm{H}_{5} \mathrm{OH}, \text { in }}+F_{\mathrm{H}_{2} \mathrm{O}, \text { in }}, \\
Q_{\text {Total }, \text { in }} & =F_{\text {Total }, \text { in }}\left(\frac{R T_{\text {in }}}{P_{\text {in }}}\right), \\
Q & =Q_{\text {Total, in }} \frac{F_{\text {Total }}}{F_{\text {Total }, \text { in }}} \frac{P_{0}}{P} \frac{T_{0}}{T}, \\
v & =\frac{Q}{A},
\end{aligned}
$$

where $F\left[\frac{\mathrm{mol}}{\mathrm{min}}\right]$ is the molar flow rate, $A\left[\mathrm{~m}^{2}\right]$ is the reforming stage reactor section area and $Q\left[\frac{\mathrm{ml}}{\mathrm{min}}\right]$ is the volumetric flow rate.

To write the mass balance in the separation stage it is necessary to model the mass transfer of hydrogen through the membrane. This mechanism of hydrogen permeation is represented by the Sieverts' Law [3], which is described as

$$
\begin{aligned}
F_{H_{2}} & =\frac{P_{e}}{\delta} S\left(\sqrt{P_{H_{2}, r}}-\sqrt{P_{H_{2}, p}}\right), \\
P_{e} & =P_{e, 0} e^{\frac{-E_{a}}{R T}},
\end{aligned}
$$

where $\delta[m]$ is the thickness of the metal membrane, $P_{e 0}$ $\left[\frac{\mathrm{mol}}{\min \cdot \mathrm{Pa}^{1 / 2} \cdot \mathrm{m}}\right]$ is the pre-exponential factor, $P_{e}\left[\frac{\mathrm{mol}}{\min \cdot \mathrm{Pa}^{1 / 2} \cdot \mathrm{m}}\right]$ is the gas permeability [5], $P_{\mathrm{H}_{2}, r}[\mathrm{~Pa}]$ is the hydrogen partial pressure in the retentate side, $P_{\mathrm{H}_{2}, p}[\mathrm{~Pa}]$ is the hydrogen partial pressure in the permeate side, $E_{a}\left[\frac{\mathrm{J}}{\mathrm{mol}}\right]$ is the apparent activation energy, $S\left[\mathrm{~m}^{2}\right]$ is the membrane's surface area and $F_{\mathrm{H}_{2}}\left[\frac{\mathrm{mol}}{\mathrm{min}}\right]$ is the permeated hydrogen flux.

\section{B. Energy Balance}

The energy balance allows to consider the temperature variation with time along the axial axis $z$ [18], as shown below:

$$
\begin{aligned}
& \rho_{g} c_{p_{g}}\left(v \frac{\partial T}{\partial z}+\left(1+\frac{\rho_{s} c_{p_{s}}}{\rho_{g} c_{p_{g}}}\right) \frac{\partial T}{\partial t}\right)=U a\left(T_{f}-T\right)+H_{r}, \\
& H_{r}=\sum_{j=1}^{N}-\Delta H_{j} r_{j} \quad j=1,2, \ldots, 4, \\
& T(0, z)=T_{0}(z) \quad z \in[0, L], \\
& T(t, 0)=T_{i n}(t) \quad \forall t>0,
\end{aligned}
$$

where $j$ is the reaction index, $\rho\left[\frac{\mathrm{Kg}}{\mathrm{m}^{3}}\right]$ stands for the solid and gas densities, $c_{p}\left[\frac{\mathrm{J}}{\mathrm{mol} \cdot \mathrm{K}}\right]$ stands for the solid and gas heat capacities, $U\left[\frac{\mathrm{J}}{\mathrm{m}^{2} \cdot \mathrm{s} \cdot \mathrm{K}}\right]$ is the global transfer heat coefficient, $a\left[\frac{\mathrm{m}^{2}}{\mathrm{~m}^{3}}\right]$ is the area per volume of reactor where heat is interchanged being equivalent to $\frac{4}{d}, T_{f}[\mathrm{~K}]$ is the temperature of the furnace, $H_{r}$ is the overall heat of reaction $\left(H_{r}\right.$ is zero in the separation stage), $\Delta H\left[\frac{\mathrm{J}}{\mathrm{mol}}\right]$ is the heat of one individual reaction and $d[\mathrm{~m}]$ is the catalytic reactor diameter. Both initial and boundary conditions are given by (9c) and (9d), respectively.
The heat capacity of a mixture of gases $c_{p}$ is equal to the weighted sum of the heat capacities of each gas, i.e.,

$$
c_{p}=\frac{\sum_{i=1}^{\mathscr{G}} P M_{i} y_{i} c_{p_{i}}}{P M_{\text {Total }}},
$$

where $c_{p_{i}}$ represents the heat capacity of each gas and $\mathscr{G}=7$ is the total number of gases. Taking into account all the gases, the calculation of the total molecular weight is carried out as follows:

$$
P M_{\text {Total }}=\sum_{i=1}^{\mathscr{G}} P M_{i} y_{i}
$$

where $P M_{i}\left[\frac{\mathrm{Kg}}{\mathrm{mol}}\right]$ is the molecular weight of each gas and $y_{i}$ [adim] is the mole fraction of each component described by

$$
y_{i}=\frac{n_{i}}{\sum_{i=1}^{\mathscr{G}} n_{i}} \leq 1 .
$$

\section{Modeling Analysis}

To solve the mathematical model presented in the previous sections, a discretization of the space in the axial direction has been performed, as represented in the following equations:

$$
\begin{aligned}
& \frac{\partial C}{\partial z}=\frac{C(z)-C(z-1)}{\Delta z}, \\
& \frac{\partial v}{\partial z}=\frac{v(z)-v(z-1)}{\Delta z}, \\
& \frac{\partial T}{\partial z}=\frac{T(z)-T(z-1)}{\Delta z},
\end{aligned}
$$

where (13), (14) and (15) are the molar concentration, the linear velocity of gases and the temperature, respectively.

Backward Euler first class finite differences was selected for the discretization, with 20 small volumes for each stage. Consequently, from the partial differential equations that describe the system, a set of ordinary differential equations have been obtained. Specifically, the discretization process results in a 320 order system (seven chemical components and the temperature per 40 differential volumes) which has been implemented in MATLAB ${ }^{\circledR}$ and SIMULINK ${ }^{\circledR}$ and integrated with the ode15s (stiff/NDF) solver.

The operating range of validity of the simulation model is: pressure from 1 to 14 bar, furnace temperature from 773.15 to $873.15 \mathrm{~K}$ and steam to carbon input ratio $(\mathrm{S} / \mathrm{C})$ from 1.8 to 3 [5]. Results shown in this section correspond to an operating point at 4 bar, $813.15 \mathrm{~K}$ temperature and S/C equal to 3 .

Figures 2(a) and 2(b) represent the static variation of the molar flow rates throughout the reaction stage. It can be seen that ethanol is completely transformed into other products. Acetaldehyde firstly increases by the ethanol dehydrogenation and then decreases because it is further reformed with water to hydrogen and carbon dioxide. Molar flow rates of hydrogen, carbon monoxide, methane and carbon dioxide are always increased until the reaction finishes while the molar flow rate of water decreases because of its participation into the reforming process. 
Figure 2(c) shows the hydrogen flowrates at the retentate and permeate sides of the membrane. The abscissa axis contains the volumes of the separation stage and, in the ordinate axis, the initial hydrogen flowrate at the retentate side is equal to the hydrogen flowrate at the end of the reformer stage, and then begins to decrease as it is filtered from the retentate toward the permeate side in order to obtain a pure hydrogen stream at system output.

Figure 2(d) shows the variation of temperature in the reformer. The temperature does not evolve in the final part of the reforming stage, where it has reached the furnace temperature. The temperature at the reforming stage output is the temperature at the input of the separation stage. Moreover, there is no temperature variation along the separation stage because in this second stage there are no chemical reactions.

Figure 2(e) shows the dynamic behavior of the system. Specifically, the time evolution of the output flowrate of pure hydrogen is plot. The operating conditions for this simulation are S/C 1.8 and 3 values with 12 and 8 bar initial pressures respectively. $\mathrm{A} \pm 4$ bar quick ramp is applied at time equal to $10 \mathrm{~min}$. $\mathrm{S} / \mathrm{C}$ has been changed from 3 to 1.8 in order to evaluate the influence of this parameter. A nonminimum phase behavior may be observed for the studied output variable.

\section{NMPC DESIGN}

\section{A. Problem formulation}

Consider the nonlinear discrete-time model of the Ethanol Steam Reformer with membrane separation:

$$
\begin{aligned}
x(k+1) & =f(x(k), u(k)), \\
y(k) & =g(x(k), u(k)),
\end{aligned}
$$

where $x \in \mathbb{R}^{280}$ is the state vector (whose components are molar concentrations of ethanol, hydrogen, carbon monoxide, methane, acetaldehyde, carbon dioxide and water), $y \in \mathbb{R}$ is the system output (volumetric flow rate of pure hydrogen), $u \in \mathbb{R}^{2}$ is the vector of manipulated inputs (ethanol and water molar flow rates) and $k \in \mathbb{Z}_{+}$is the discrete-time variable.

\section{B. Prediction Model}

To solve the control problem of $H_{2}$ tracking while minimizing the consumed ethanol, an NMPC strategy can be designed given its advantageous features related to the control input computation based on an available model while handling system constraints [19]. In order to obtain the nonlinear prediction model, the sampling data technique of the continuous model (3a) and (7) is used [20]. This method computes the continuous evolution of the nonlinear system model by means of the integration of its differential equations, but only collecting information of that output at the sampling time of the discrete time control design.

\section{Constraints}

The system is subject to physical and chemical limitations, as well as operational requirements. Hence, restrictions should be defined such that the overall closed-loop control system must satisfy them for all time instants in order to ensure the proper system performance. Thus, the constraints on manipulated inputs, output and model states, respectively, into the proposed NMPC design are outlined as follows:

$$
\begin{aligned}
0.0018 & \leq u_{\text {eth }}(k+m \mid k) \leq 0.0024, \\
0.00876 & \leq u_{\text {wat }}(k+m \mid k) \leq 0.0108, \\
0 & \leq y(k+m \mid k) \leq 70.34 \\
x^{\min } & \leq x(k+m \mid k) \leq x^{\max } .
\end{aligned}
$$

\section{Cost Function}

Two control objectives are defined. One consists in the minimization of the output error in the amount of demanded hydrogen. The other one, consists in minimizing the total hydrogen production cost, considering this cost proportional to the ethanol consumption. From both objectives, the cost function $J$ is defined as:

$$
J(k)=\sum_{m=0}^{N-1}\left[J_{1}+J_{2}\right]
$$

with

$$
\begin{aligned}
& J_{1}=\left\|y(k+m \mid k)-r_{y}(k \mid k)\right\|_{Q}^{2}, \\
& J_{2}=\left\|u_{e t h}(k+m \mid k)-u_{e t h}^{\min }\right\|_{R}^{2},
\end{aligned}
$$

for all $m \in\{0,2, \ldots, N-1\}$, where $y(k+m \mid k)$ is the predicted output variable at time instant $k$ that corresponds to the hydrogen volumetric flow at the system output, $N$ is the prediction horizon and $r_{y}(k \mid k)$ is the system reference, i.e., the hydrogen volumetric flow amount required at each time instant and $u_{\text {eth }}^{\min }$ corresponds to the minimum ethanol inflow, i.e., $0.0018 \mathrm{~mol} / \mathrm{min}$ according to (18a). Moreover, $Q$ and $R$ are weighting matrices assigned to prioritize each control objective, which are normalized as follows:

$$
\begin{aligned}
& Q=\frac{q}{\left[y^{\mathrm{max}}-y^{\mathrm{min}}\right]^{2}}, \\
& R=\frac{r}{\left[u^{\mathrm{max}}-u^{\mathrm{min}}\right]^{2}},
\end{aligned}
$$

with $q$ and $r$ being the prioritization factors without normalization. Besides, $\|\cdot\|$ denotes the weighted Euclidean norm.

\section{E. Optimization Problem}

Combining model equations, the constraints on inputs in (18a)-(18b), output in (18c) and states in (18d), and the objective function in (19), the open-loop finite-time optimization problem behind the design of the NMPC controller is stated as follows:

$$
\min _{u(k \mid k), \ldots, u(k+N-1 \mid k)} J(k)
$$

subject to:

$$
\begin{aligned}
x(k+1+m \mid k) & =f(x(k+m \mid k), u(k+m \mid k)), \\
y(k+m \mid k) & =g(x(k+m \mid k), u(k+m \mid k)), \\
x(k \mid k) & =\hat{x}(0 \mid k), \\
u^{\min } & \leq u(k+m \mid k) \leq u^{\max }, \\
y^{\min } & \leq y(k+m \mid k) \leq y^{\max }, \\
x^{\min } & \leq x(k+m+1 \mid k) \leq x^{\max },
\end{aligned}
$$




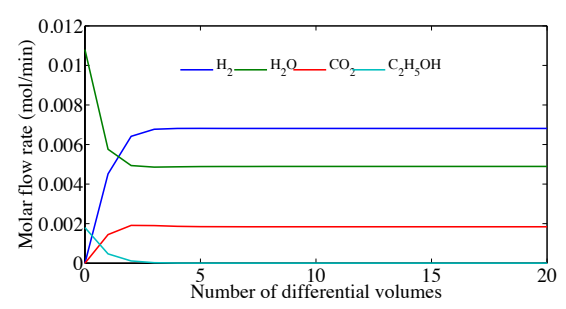

(a)

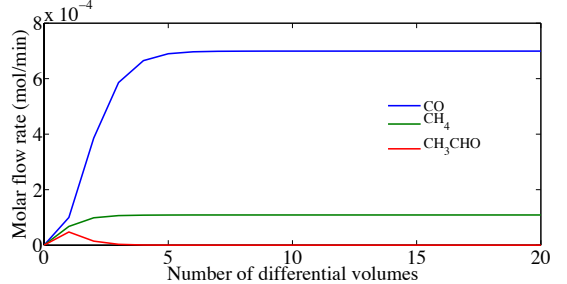

(b)

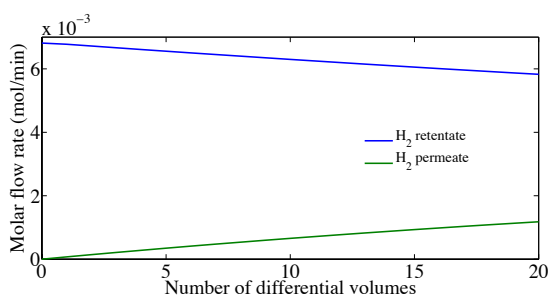

(c)

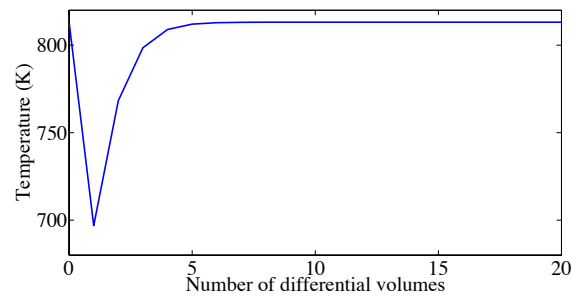

(d)

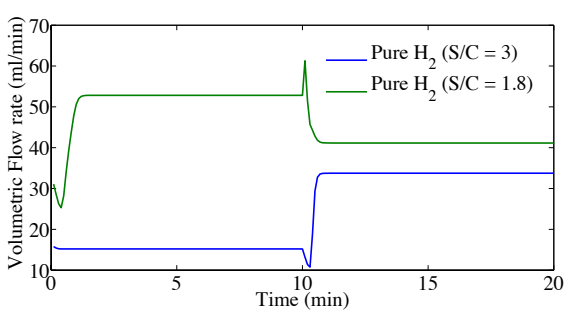

(e)

Fig. 2. System analysis: (a) Static profiles of the most abundant chemical species in reformer stage, (b) Static profiles of minor chemical species in reformer stage, (c) Static profiles of the molar flow rate of hydrogen in membrane separation stage, (d) Temperature profile in reformer stage, (e) System output dynamic profile of pure hydrogen volumetric flow rate

for all $m \in\{0,2, \ldots, N-1\}$, where $\hat{x}(0 \mid k)$ is the initial condition of the states. According to the receding horizon strategy of the NMPC controller, only the first component of the resultant optimal sequence of control actions $u^{*}(k \mid k), \ldots, u^{*}(k+N-1 \mid k)$ is applied to the process at each $\Delta t$.

\section{Simulation Results and Discussion}

The performance of the presented closed-loop scheme based on NMPC is assessed by the simulation curves, the Root Mean Squared Error (RMSE) and the real-time computing (RTC) corresponding to different simulation scenarios, as it can be seen in Table I. The RMSE is defined as key performance index:

$$
K P I_{e}=\sqrt{\frac{1}{M} \sum_{k=1}^{M}\left(y_{\mathrm{H}_{2}}(k)-r_{\mathrm{H}_{2}}(k)\right)^{2}},
$$

where $y_{H_{2}}(k)$ is the hydrogen volumetric outflow rate and $r_{H_{2}}(k)$ is the hydrogen outflow reference, both along a simulation scenario of length $M$.

TABLE I

NMPC RESUlTS AND PARAMETERS

\begin{tabular}{cccccc}
\hline \multicolumn{3}{c}{ Parameters } & \multicolumn{2}{c}{ Results } \\
\hline$T_{s}[\mathrm{~min}]$ & $H_{p}$ & $q$ & $r$ & $K P I_{r t c}[\mathrm{~min}]$ & $K P I_{e}$ \\
\hline 0.65 & 3 & 1 & {$[0: 0.25: 0.5]$} & 5.188 & 0.0742 \\
0.2 & 10 & 1 & 0 & 79.660 & 0.1468 \\
0.1 & 20 & 1 & 0 & $>80$ & 0.0530 \\
\hline
\end{tabular}

Several simulations have been performed using different NMPC parameters; using the parameters of the first raw of Table I, the simulation curves of Figure 3(a) are obtained.
The operating pressure and furnace temperature are 4 bar and $813.15 \mathrm{~K}$. The system inputs for this simulation case are shown in Figure 3(d). Different options for $r$ are considered. With more penalization in the production cost (higher values of $r$ ), lower ethanol inflow is used. However, as an unavoidable consequence, the hydrogen outflow does not follow the setpoint when its values are high (steady-state error). Furthermore, computation time lays within the $80 \mathrm{~min}$ of simulated time $(M=80)$.

On the other hand, the simulation curves of Figure 3(b) are obtained with the parameters at the second row of Table I (second case). In this case, the cost penalization $r$ is cancelled and the sample time has been decreased. The pure hydrogen outflow setpoint values and the pressure and furnace temperature operating conditions are the same as in the later case. The red line is the time-varying reference and the blue line corresponds with the pure hydrogen outflow. Since $\mathrm{r}=0$, the tracking is properly achieved. The system inputs for this simulation case are shown in Figure 3(e), where it is possible to see that both inputs have quite smooth evolutions. However, the computation time is at its limit for a real implementation.

Finally, the parameters of the third row of Table I are used to obtain the results shown in Figure 3(c) for the hydrogen outflow, and Figure 3(f) for the system inputs (manipulated variables) with operational conditions at $10 \mathrm{bar}$ of pressure and $873.15 \mathrm{~K}$ of furnace temperature. Both Figures present how the system works when the reference is trying to push the system throughout its limits. Hence, ethanol and water constraints are working to keep a safety system. Also, a zoomed plot is shown to see, in more detail, how the dynamic system close to a critical point is evolved. 


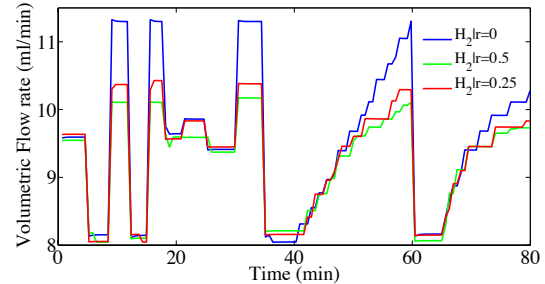

(a)

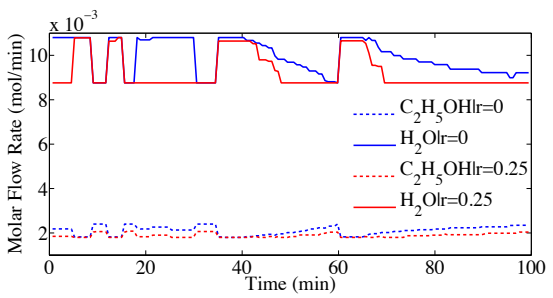

(d)

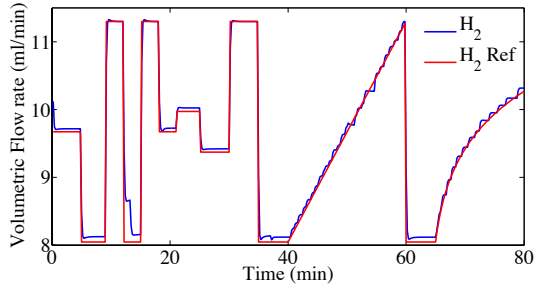

(b)

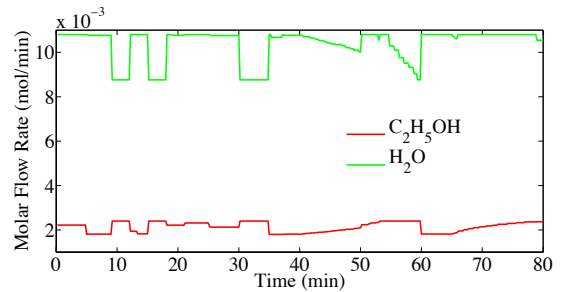

(e)

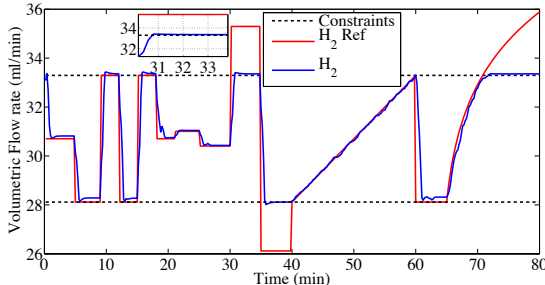

(c)

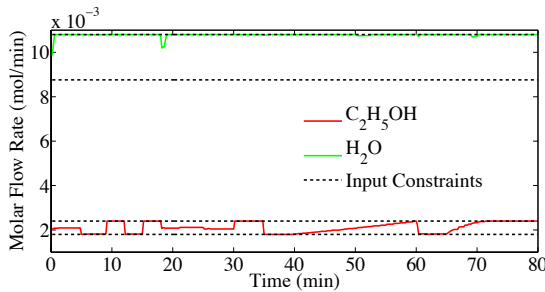

(f)

Fig. 3. Simulation results: (a) Pure Hydrogen output of the closed-loop system with different cost production penalties, (b) Pure Hydrogen output of the closed-loop system, (c) Constraints and Pure Hydrogen output of the closed-loop system, (d) Ethanol and water control actions of the closed-loop system with different cost production penalties, (e) Ethanol and water control actions of the closed-loop system, (f) Constraints, ethanol and water control actions of the closed-loop system

\section{CONCLUSiONS}

This paper proposes the dynamical model of an ethanol steam reformer, with a chemical complex reforming stage and a membrane-based $\mathrm{H}_{2}$ separation. Considering this model, which includes the dynamical relations based on both mass and energy balances, a closed-loop control scheme based on the sample data technique NMPC is proposed, designed and discussed. Simulation results are presented for different system conditions and controller parameters in order to evaluate the effectiveness and performance of the proposed control scheme when different values of pure hydrogen outflow are required.

\section{ACKNOWLEDGEMENTS}

This work has been partially funded by the Spanish national projects MICAPEM (ref. DPI2015-69286-C3-2-R, MINECO/FEDER) y ECOCIS (ref. DPI2013-48243-C2-1R). J. Llorca is Serra Húnter Fellow and is grateful to ICREA Academia program and MINECO/FEDER grant ENE201563969-R.

\section{REFERENCES}

[1] O. Z. Sharaf, M. F. Orhan, An overview of fuel cell technology: Fundamentals and applications, Renewable and Sustainable Energy Reviews 32 (0) (2014) 810-853.

[2] Holladay J, Hu J, King D, Wang Y. An overview of hydrogen production technologies. Catalysis Today 2010;139:244-60.

[3] R. Koch, E. López, N. J. Divins, M. Allué, A. Jossen, J. Riera, J. Llorca, Ethanol catalytic membrane reformer for direct PEM FC feeding, International Journal of Hydrogen Energy 38 (14) (2013) $5605-5615$.

[4] García VM, López E, Serra M, Llorca J, Riera J. Dynamic modeling and controllability analysis of an ethanol reformer for fuel cell application. International Journal of Hydrogen Energy 2010;35:976875 .
[5] R. Espinal, A. Anzola, E. Adrover, M. Roig, R. Chimentao, F. Medina, E. López, D. Borio, J. Llorca, Durable ethanol steam reforming in a catalytic membrane reactor at moderate temperature over cobalt hydrotalcite, International Journal of Hydrogen Energy 39 (21) (2014) 10902-10910.

[6] I.Uriz, G.Arzamendi, E.López, J.Llorca and L.M.Gandía. Computational uid dynamics simulation of ethanol steam reforming in catalytic wall michrochannels. Chemical Engineering Journal, 167(3):603$609,2011$.

[7] Irandoust, S. y Andersson, B. Monolithic Catalysts for Nonautomobile Applications, Catal. Rev. Sci. Eng., 1988(30), 343

[8] Hayes, R.E. y Kolaczkowski, S.T. Introduction to Catalytic Combustion, Gordon and Breach Sci. Pub., Amsterdam, 1997.

[9] G.Groppi, A.Betolli, E. Tronconi, P. Forzatti, Comparison of Lumped and Distributed Models of Monolith Reactors, Chem. Eng. Sci., 1995 (50) 2705.

[10] G.Groppi, A.Betolli, E. Tronconi, P. Forzatti, Mathematical Models of Catalytic Combustors. Catal. Rev. Sci. Eng., 1999 (41) 227.

[11] James, A.; Brindley, J.; McIntosh, A.C. Classification of Behavior in a Steady Plug-Flow Model of Cathalytic Combustion, Chem. Eng. Sci., 2001 (56)4649.

[12] Irandoust, S. y Andersson, B. Monolithic Catalysts for Nonautomobile Applications,Catal. Rev. Sci. Eng., 1988(30), 343.

[13] G.Groppi, A.Betolli, E. Tronconi, P. Forzatti, Comparison of Lumped and Distributed Models of Monolith Reactors, Chem. Eng. Sci., 1995 (50) 2705.

[14] A.Cornelio, Dynamic Modelling of An Industrial Ethylene Oxide Reactor, Indian Chem. Eng. 2006 (48) 164.

[15] Luyben WL. Process modeling, simulation and control for chemical engineers. Chemical engineering. 2nd ed. New York: MacGraw-Hill; 1989.

[16] H. Fogler. Elements of chemichal reaction engineering. 3th ed. Prentice-Hall of India, New Delhi (2004), p.570.

[17] H. Scott Fogler. Essentials of chemical reaction engineering. International Edition. Boston: Pearson Education Inc.(2011), p.286.

[18] Avi.A.Cornelio. Dynamic Modelling of An Industrial Ethylene Oxide Reactor. Indian Chemical Engr. Section A, Vol.48,No.3,July-Sept. 2006, p. 172.

[19] Lars Grüne, Jürgen Pannek. Nonlinear Model Predictive Control, Springer, 2011.

[20] Rolf Findeisen, Tobias Raff, and Frank Allgöwer. Sampled-Data Model Predictive Control for Constrained Continuous Time Systems. Institute for Systems Theory and Automatic Control, University of Stuttgart, Germany, 2009. 